\title{
Larger or Broader: Performance Implications of Size and Diversity of the Knowledge Worker's Egocentric Network
}

\section{Liang Ghen (陈亮) ${ }^{1}$ and Guy G. Gable ${ }^{2}$}

'East China University of Science and Technology, China, and ${ }^{2}$ Queensland University of Technology, Australia

ABSTRACT Management scholars and practitioners emphasize the importance of the size and diversity of a knowledge worker's social network. Constraints on knowledge workers' time and energy suggest that more is not always better. Further, why and how larger networks contribute to valuable outcomes deserves further understanding. In this study, we offer hypotheses to shed insight on the question of the diminishing returns of large networks and the specific form of network diversity that may contribute to innovative performance among knowledge workers. We tested our hypotheses using data collected from 93 R\&D engineers in a Sino-German automobile electronics company located in China. Study findings identified an inflection point, confirming our hypothesis that the size of the knowledge worker's egocentric network has an inverted U-shaped effect on job performance. We further demonstrate that network dispersion richness (the number of cohorts that the focal employee has connections to) rather than network dispersion evenness (equal distribution of ties across the cohorts) has more influence on the knowledge worker's job performance. Additionally, we found that the curvilinear effect of network size is fully mediated by network dispersion richness. Implications for future research on social networks in China and Western contexts are discussed.

KEYwORDS knowledge worker, network dispersion evenness, network dispersion richness, network diversity, network size, performance

\section{更多或更广：知识员工个人中心网络大小和多样性对绩效的影响}

\section{摘要}

管理学者和实践者纷纷强调知识员工关系网络大小和多样性的重要性。然而知识员工的时间 与精力的有限性却暗示关系数量并不是越多越好。为什么更多数量的员工关系会带来效益, 这种效益是如何产生的, 这两个问题值得进一步探讨。在本研究中，我们通过假设检验来深 入了解更多数量员工关系的递减效益，以及关系网络多样性对知识员工创新绩效的作用。经 验数据来自一家位于中国的中德合资汽车电子有限公司，包括93位研发工程师。研究结果显 示员工关系数量对知识员工绩效的正面影响有一个转折点, 从而证明关于知识员工关系数量 对其绩效有倒U型影响的假设。我们进一步证实知识员工关系网络的分布范围，相较于关系 网络的分布均衡性，对其绩效影响更显著。此外，我们发现知识员工关系数量对其绩效的倒 U型影响完全被员工关系网络的分布范围所中介。最后，我们提出了在中国和西方背詈下进 一步研究社会网络的建议。

关键词：知识员工，关系网络分布均衡性，关系网络分布范围，关系网络多样性，关系网络 大小，绩效 


\section{INTRODUGTION}

With the goal of increasing employee social capital, many scholars offer suggestions on how to best configure an individual's social network. Some emphasize the importance of the number of contacts while others stress the value of diverse contacts. Support for the first position comes from scholars who have empirically demonstrated that the quantity of contacts is positively related to: the amount and diversity of organizational information to which an individual has access (Anderson, 2008; Seibert, Kraimer, \& Liden, 2001); individual performance (Allen, 1977; Cross \& Cummings, 2004); and organizational innovation capacity (Mehra, Kilduff, \& Brass, 2001; Smith, Collins, \& Clark, 2005). There are difficulties with this perspective. Sole emphasis on the number of contacts implies a continuous, linear relationship between an individual's egocentric network size and their job performance. However, this ignores the scarcity of the employees' time and the effort required to initiate, foster, and maintain relationships (Latour \& Woolgar, 1979). There will be a finite number of productive relationships that any individual can effectively build and maintain (McFadyen \& Cannella, 2004), and there is an obvious trade-off between the time and energy spent building and maintaining relationships with that spent on innovation.

There is also research suggesting value from diverse contacts. Granovetter (1973) and Lin, Ensel, and Vaughn (1981) suggest that people with a wider social network are more likely to gather relevant information; Campbell, Marsden, and Hurlbert (1986) find that network diversity is positively related to individual socioeconomic status; Burt (1992) argues that individuals with ties spanning boundaries can improve job performance; and Pfeffer (2010) proposes that diversity of contacts is useful for obtaining power. In the ecological literature, diversity can be dissected into two components: dispersion richness and dispersion evenness (Alatalo, 1981). Dispersion richness refers to the total number of categories (Peet, 1974), and dispersion evenness is the relative distribution among these categories (Lloyd \& Ghelardi, 1964). For example, Employee A has contacts from $k$ departments in an organization which consists of $K(K=k)$ departments; the value of dispersion richness is $k$ and evenness reaches its maximum when the number of contacts in each department is equal and $k \geq K$; and the more the relative quantity among departments differs the lower the evenness (Alatalo, 1981). To gauge network diversity, previous studies, e.g., Cummings (2004), Oh, Chung, and Labianca (2004), Reagans and McEvily (2003), and Reagans and Zuckerman (2001), have used either Teachman's index or Blau's index, both of which combine dispersion richness and evenness in a single value (Harrison \& Klein, 2007; Stirling \& Wilsey, 2001). None have evaluated the relative influence of dispersion richness versus dispersion evenness on innovative performance.

Given that each perspective emphasizes the importance of either network size in one extreme or network diversity in the other, little is known about the rela- 
tionship between them; it is simply assumed that growth in network size will result in increased network diversity (Campbell et al., 1986). Thus, there is value from investigating the relative importance of quantity (size) and diversity of contacts in arriving at a deeper understanding of the impact of the social network.

This article reports a study of $93 \mathrm{R} \& \mathrm{D}$ employees of a Sino-German joint venture company operating in China that supplies carmakers with innovative automobile electronics. The 93 engineers utilize their accumulated knowledge of electronics and engineering to solve problems and create new technologies and products. In this study, the unit of analysis is the individual knowledge worker - the $\mathrm{R} \& \mathrm{D}$ employee. The aim of this article is to examine influences of the knowledge worker's egocentric network on the R\&D employee's innovative job performance. We explore whether the traditionally assumed linear relationship between performance and network size holds true, investigate the relative importance of quantity and diversity of contacts, and unpack the concept of diversity by examining the relative influence of dispersion richness and dispersion evenness.

\section{THEORETICAL BACKGROUND AND HYPOTHESES}

\section{Knowledge Creation and the Role of Social Networks}

The problems that confront knowledge workers are often novel and challenging. Knowledge workers need diverse information and expertise to resolve these problems. Building and maintaining ties to different cohorts of colleagues and establishing knowledge exchange networks is essential to accessing the diverse resources needed for innovation. Research suggests that knowledge workers prefer to seek information and expertise from peers rather than from documents (Allen, 1977; Cross, Parker, Prusak, \& Borgatti, 2001), even where they have easy and convenient access to the internet and the firm's IT-based knowledge repository (Cross \& Sproull, 2004). A key reason for this preference is that 'in knowledge creation, information exchange is frequently emergent' and knowledge seekers are often unable to express a priori their specific knowledge needs (McFadyen \& Cannella, 2004: 737). In interpersonal exchanges, knowledge givers are able 'to adapt flexibly and respond rapidly to communicated needs' (Allen, 1970: 14), and can more effectively cope with the uncertain nature of such needs. Thus, the knowledge worker's egocentric network plays a key role in their creation of new knowledge.

The knowledge worker's contacts have been divided into various cohorts, which are considered alternative sources of resources employees require to accomplish their tasks (Oh et al., 2004). These cohorts are defined from the focal employee's perspective. The first cohort includes those within the focal employee's department. These colleagues serve as important sources of information from which technical 
ideas often originate in R\&D departments (Allen, 1977). They may provide information and knowledge on some important development, which could directly influence the specific tasks the focal individual is assigned (Allen, 1970). Knowledge workers in a single department are more likely to share similar background experience and expertise, face similar problems, and deal with similar tasks.

The second cohort includes those colleagues who are outside the focal employee's department yet still within the organization. These individuals may have disparate perspectives and skills (Mehra, Dixon, Brass, \& Robertson, 2006) and may have different beliefs about knowledge importance (Wong, 2008). Research shows that cross-department ties facilitate valuable knowledge exchange (Hansen, 2000; Tsai, 2001) and are positively correlated with performance (Allen, 1977; Cross \& Cummings, 2004); hence there is value in sharing knowledge across functional boundaries (Clark \& Fujimoto, 1991; Davis \& Lawrence, 1977).

The third cohort includes those colleagues higher in the organizational hierarchy, who can acquire resources necessary for others to complete tasks. Previous research suggests that those higher in the hierarchy can access information not available to subordinates (Galbraith, 1977), and have more contacts outside the organization as well as with other managers in different units of the organization (Carroll \& Teo, 1996; Stevenson \& Gilly, 1991). They have unique and valuable resources such as power and decision-making authority (Mehra et al., 2006), influence (Brass, 1984), and prestige (De Graaf \& Flap, 1988; Lin, 1999; Marsden \& Hurlbert, 1988), and may have greater breadth of information and perspective (Galbraith, 1977). Ties to such people can enable access to these resources and help improve job performance (Cross \& Cummings, 2004). Moreover, hierarchical superiors are valued for their provision of solutions, referrals, validation, and legitimation (Cross \& Sproull, 2004). Access to leaders in other departments can also facilitate engaging the other departments to assist (Perry-Smith \& Shalley, 2003). Connections to those higher in the hierarchy enable the individual to exercise influence upward, and to access resources needed to accomplish tasks (Brass, 1984, 1992; Seibert et al., 2001).

Though extra-organizational ties may have some impact on job performance, this article focuses on intra-organizational ties. Internal firm-specific knowledge is the basis of the products developed by the $\mathrm{R} \& \mathrm{D}$ department in the study organization. Also, obtaining data on extra-organizational connections was fraught with difficulty because of issues such as confidentiality. Our focus on internal knowledge transfer is supported by the findings of recent research by Criscuolo, Dahlander, and Salter (2009) that suggests the diversity of extra-organizational ties is not significantly correlated with an individual's 'innovative status' (i.e., recognition by their colleagues for developing new, innovative solutions). Szulanski (1996: 27) also suggests that 'because internal transfers typically are hindered less by confidentiality and legal obstacles than external transfers, they could be faster and initially 
less complicated' and argues that 'in an era when continuous organizational learning and relentless performance improvement are needed to remain competitive, companies must increasingly resort to the internal transfer of capabilities'.

\section{Hypotheses}

Network size is a primary social network measure of an individuals' access to information and knowledge (Gabbay \& Leenders, 2001). Because each of an actor's ties represents a conduit to information and knowledge, more ties should mean greater access to these resources. Just as there will be some base-line level of information, knowledge, and resources below which a knowledge worker would be unable to accomplish tasks, so one might anticipate there will also be a minimum size of the knowledge worker's egocentric network, below which they would not be able to perform their role efficiently (Allen, 1977).

Increasing the number of contacts comes at a cost. Interpersonal relationships take time and energy to identify, initiate, develop, and maintain (Luo, 2011; McFadyen \& Cannella, 2004). Any increase in contacts will increase the number of communications (Allen, 1977), and consequently consume more time and energy. Different cohort relationships take time and energy for different reasons. For contacts within the same department where individuals must work together toward a common goal, effort is required to improve mutual understanding and to develop a shared language. Ancona and Caldwell (1992) found that teams need good internal communication in order to set goals and priorities and to develop effective group processes. Interactions across departmental boundaries consume additional time and energy owing to the difficulties associated with physical distance and the coordination of different sub-cultures and norms across departments. Further, social ties that are 'valuable in facilitating certain actions may be useless or even harmful for others' (Coleman, 1988: S98). For example, strong norms and strong social identification may be useful for group cohesion but can limit openness to information (Nahapiet \& Ghoshal, 1998) and may impede learning (Simon \& Davies, 1996). Knowledge workers have a finite amount of time and energy, and increasing the number of ties consumes more time and energy which in turn reduces the time and energy available for knowledge creation activities (Latour \& Woolgar, 1979). Increasing the number of ties beyond a certain point may lead to diminishing or negative returns to performance. McFadyen and Cannella (2004) in a study looking at co-authorship within a group of 173 research scientists provide some preliminary evidence that the relationship between social capital and the amount of knowledge created is not a simple linear function, and that on the contrary, increasing the number of relationships eventually leads to diminishing returns. Additionally, excessive contacts will reduce the time available to spend with each contact, resulting in dilution of the total value of information and knowledge received (Allen, 1977). 
In summary, we suggest when intra-organizational ties are too few, the knowledge and information accessible via these ties is inadequate to support the focal individual's knowledge creation needs; when intra-organizational ties are excessive, they will consume time and energy needed for knowledge creation. Too few or too many ties will negatively affect job performance. Stated formally:

Hypothesis 1: The size of a knowledge worker's egocentric network will have an inverted $U$-shaped relationship with the knowledge worker's job performance.

Research has revealed the importance of diverse knowledge in the creation of innovative new products (see, e.g., Hargadon \& Sutton, 1997). Diverse network ties serve as conduits to different knowledge and information sources. In a closed and less diverse network, the information available tends to be homogeneous and thus often redundant (Burt, 1992; Gargiulo \& Benassi, 2000). Also, in less diverse networks, judgment about knowledge importance tends to be similar, which can hinder the acceptance and integration of new knowledge (Wong, 2008). A more diverse perspective should increase the likelihood that one understands how to use relevant information located in socially distant regions of a network (Cross \& Cummings, 2004). Since social networks that span boundaries allow knowledge workers to access more potentially relevant knowledge when framing problems and to obtain the information needed to solve problems, such social networks should improve innovation performance (Cross \& Cummings, 2004).

Harrison and Klein (2007: 1200) distinguish three types of diversity: (i) separation - 'differences in position or opinion among unit members', e.g., dissimilar values or attitudes; (ii) variety - 'differences in kind or category, primarily of information, knowledge, or experience among unit members'; and (iii) disparity 'differences in concentration of valued social assets or resources such as pay and status among unit members'. Given our emphasis on knowledge access, the appropriate type of diversity in the context of our study is 'variety'. Harrison and Klein (2007) identify two indices that operationalize variety: Blau's index and Teachman's (entropy) index. Both indices sum categories weighted by their relative quantity and hence depend on dispersion richness and evenness (Harrison \& Klein, 2007; Stirling \& Wilsey, 2001). Dispersion richness is the total number of categories (Peet, 1974). Dispersion evenness is defined as the distribution of relative abundance among categories (Lloyd \& Ghelardi, 1964). These concepts can be better understood if we consider the case of three knowledge workers who we will call knowledge worker A (KW-A), knowledge worker B (KW-B) and knowledge worker $\mathrm{C}(\mathrm{KW}-\mathrm{C})$. Recall the knowledge worker's intra-organizational contacts can be segmented into three cohorts: (i) those within the same department as the focal individual; (ii) those outside the focal individual's department but within the organization; and (iii) those at a higher level in the organizational hierarchy. If KW-A makes a connection to only one of the three cohorts, while 
KW-B has contacts across all three cohorts then KW-B has a richer dispersion of contacts than KW-A and the diversity of KW-B's egocentric network is greater than that of KW-A. On the other hand KW-C has the same number of contacts as $\mathrm{KW}-\mathrm{B}$ and these contacts are also spread across all three cohorts, but the distribution of connections between KW-B and KW-C differs. The communication links of KW-C are equally distributed among the three cohorts, while connections to one of the three cohorts dominate for KW-B. In this case KW-C has a more evenly dispersed egocentric network than KW-B and thus KW-C's contact diversity is greater than KW-B's, according to both Blau's index and Teachman's (entropy) index.

Scholars who have used either Blau's index or entropy to measure diversity in their social network research include Cummings (2004), Oh et al. (2004), Reagans and McEvily (2003), and Reagans and Zuckerman (2001). These scholars, however, did not distinguish between the relative effects of dispersion richness and dispersion evenness. We expect that these dispersion dimensions will have different implications for innovative performance, as we explain below.

The team level study evidences that the unevenness in team member power decreased team performance by interrupting the flow of information (Eisenhardt \& Bourgeois, 1988). As network ties provide conduits to information and knowledge, unevenly distributed connections among cohorts indicate that one specific knowledge base would dominate the source of expertise, and hence would lead to bias over the importance of disparate knowledge sources; while evenly distributed contacts among cohorts would allow the ego to have an equal opportunity to access differing expertise, and to form a relatively balanced view on the value of various knowledge bases. Harrison and Klein (2007) suggest that inequality would lead to suppression of innovation. Accordingly, we might conclude that dispersion evenness should be positively correlated with performance, and state formally:

Hypothesis 2: The dispersion evenness of a knowledge worker's egocentric network will relate positively to the knowledge worker's job performance.

According to Burt's theory (1992), networks rich in structural holes can provide ego with the benefit of differing access to information. The wider people cast their social nets, the more likely they are to gather information about a specific job (Lin et al., 1981). Having broad networks can ease the transfer of useful knowledge, and increase a person's ability to convey complex ideas to diverse audiences, because behaviors that ease knowledge transfer, such as framing communications in a language that a contact can understand, are part of their everyday network activities (Reagans \& McEvily, 2003). By broadening one's perspective, diverse information can help individuals 'make sense of equivocal events in their environment, notice emerging trends and problems, and 
achieve higher performance' (Anderson, 2008: 51). Innovative product development tasks demand different bases of expertise (Kratzer, Leenders, \& Van Engelen, 2008). Thus, we suggest that a broad network should be highly correlated with performance, and state formally:

Hypothesis 3: The dispersion richness of a knowledge worker's egocentric network will relate to the knowledge worker's job performance.

Campbell et al. (1986) postulate that larger networks represent greater diversity because the homogeneity of contacts' attributes decreases as the number of contacts increases. Hill (1973) also suggests that larger size will lead to an increase in diversity. While we agree that the number of the knowledge worker's contacts is helpful, because the larger this number, the 'more likely' they are to be diverse, we believe the amount of increase in diversity depends on how the growth in network size occurs. As diversity is comprised of both dispersion richness and dispersion evenness, we analyze how the increase of network size affects dispersion richness and dispersion evenness separately.

There are two ways in which the knowledge worker's egocentric network size could increase: a new contact could come from either a cohort where the focal employee already has connections or a cohort where the focal employee currently has no connections. Richness grows as the number of contacts increases in the latter instance, but does not change in the former. Table la shows an example of how the network size and dispersion richness for a new employee might develop. This is a special case in which each new connection is from a different cohort and thus richness grows at the maximum rate (before the employee joins the company he or she has no connections - Step 1). Table $1 \mathrm{~b}$ is another example; this time each new connection is from the same cohort, thus richness doesn't grow beyond the one cohort. From these examples it can be seen that the number of contacts is a necessary requirement of a rich egocentric network.

The relationship between network size and dispersion evenness is best demonstrated by considering another hypothetical scenario. Employee D has a network of

Table la. Example of maximum change in richness with size growth

\begin{tabular}{lcccccc}
\hline \hline & $\begin{array}{c}\text { The number of } \\
\text { contacts in Cohort 1 }\end{array}$ & $\begin{array}{c}\text { The number of } \\
\text { contacts in Cohort 2 }\end{array}$ & $\begin{array}{c}\text { The number of } \\
\text { contacts in Cohort 3 }\end{array}$ & $\begin{array}{c}\text { Network } \\
\text { richness }\end{array}$ & $\begin{array}{c}\text { Netwoork } \\
\text { size }\end{array}$ & Diversity \\
\hline Step 1 & 0 & 0 & 0 & 0 & 0 & 0 \\
Step 2 & 1 & 0 & 0 & 1 & 1 & 0 \\
Step 3 & 1 & 1 & 0 & 2 & 2 & 0.5 \\
Step 4 & 1 & 1 & 1 & 3 & 3 & 0.67 \\
\hline \hline
\end{tabular}


Table lb. Example of minimum change in richness with size growth

\begin{tabular}{lcccccc}
\hline \hline & $\begin{array}{c}\text { The number of } \\
\text { contacts in Cohort 1 }\end{array}$ & $\begin{array}{c}\text { The number of } \\
\text { contacts in Cohort 2 }\end{array}$ & $\begin{array}{c}\text { The number of } \\
\text { contacts in Cohort 3 }\end{array}$ & $\begin{array}{c}\text { Network } \\
\text { richness }\end{array}$ & $\begin{array}{c}\text { Network } \\
\text { size }\end{array}$ & Diversity \\
\hline Step 1 & 0 & 0 & 0 & 0 & 0 & 0 \\
Step 2 & 1 & 0 & 0 & 1 & 1 & 0 \\
Step 3 & 2 & 0 & 0 & 1 & 2 & 0 \\
Step 4 & 3 & 0 & 0 & 1 & 3 & 0 \\
\hline \hline
\end{tabular}

Figure 1. The relationship between network size and dispersion evenness

\begin{tabular}{ccccccc} 
Step & & Size \\
\hline 1 & & & & & \\
3
\end{tabular}

maximum evenness with the same number of connections $(n)$ in each of the three cohorts (Step I, Fig. 1). Figure 1 shows the potential ways in which evenness might change as Employee D's network size increases (there are four types of size growth in this case). In Step 2, the number of contacts has increased by one with the result that the number of connections to one of the cohorts is greater than the number of connections to the other two cohorts. Steps 3 and 4 demonstrate that there are a number of possible ways in which further new contacts might be added. More details regarding the impact of size growth on evenness are presented in Tables $2 \mathrm{a}-\mathrm{d}$ (where, for convenience, the value of $n$ is set to be 5) according to Way 1, 2, 3 and 4, respectively. For network size growing under Way 1 (Table 2a), the value of evenness goes down and then up, back to its maximum again in Step 4; for Way 2 (Table 2b), evenness decreases and then increases and finally decreases; for Way 3 (Table 2c) the result of evenness heads down and then turns up, but its value in Step 4 is lower than its initial value. While for Way 4 (Table 2d), evenness constantly decreases. These results prove that there is no certain correlation between size and dispersion evenness. Hence, we do not posit a mediating role of dispersion evenness.

Since network dispersion richness is proposed to be positively correlated with job performance, and network size is the necessary condition of network dispersion richness, we suggest network dispersion richness mediates the effect of network size on job performance, and state formally: 
Table 2a. Example of change in evenness with size growing under way 1

\begin{tabular}{lcccccc}
\hline \hline & $\begin{array}{c}\text { The number of } \\
\text { contacts in Colort 1 }\end{array}$ & $\begin{array}{c}\text { The number of } \\
\text { contacts in Cohort 2 }\end{array}$ & $\begin{array}{c}\text { The number of } \\
\text { contacts in Cohort 3 }\end{array}$ & $\begin{array}{c}\text { Network } \\
\text { evenness }\end{array}$ & $\begin{array}{c}\text { Network } \\
\text { size }\end{array}$ & Diversity \\
\hline Step 1 & 5 & 5 & 5 & 1 & 15 & 0.67 \\
Step 2 & 6 & 5 & 5 & 0.99 & 16 & 0.66 \\
Step 3 & 6 & 6 & 5 & 0.99 & 17 & 0.66 \\
Step 4 & 6 & 6 & 6 & 1 & 18 & 0.67 \\
\hline \hline
\end{tabular}

Table 2b. Example of change in evenness with size growing under way 2

\begin{tabular}{lcccccc}
\hline \hline & $\begin{array}{c}\text { The number of } \\
\text { contacts in Cohort 1 }\end{array}$ & $\begin{array}{c}\text { The number of } \\
\text { contacts in Cohort 2 }\end{array}$ & $\begin{array}{c}\text { The number of } \\
\text { contacts in Cohort 3 }\end{array}$ & $\begin{array}{c}\text { Network } \\
\text { evenness }\end{array}$ & $\begin{array}{c}\text { Network } \\
\text { size }\end{array}$ & Diversity \\
\hline Step 1 & 5 & 5 & 5 & 1 & 15 & 0.67 \\
Step 2 & 6 & 5 & 5 & 0.99 & 16 & 0.66 \\
Step 3 & 6 & 6 & 5 & 0.99 & 17 & 0.66 \\
Step 4 & 7 & 6 & 5 & 0.98 & 18 & 0.66 \\
\hline \hline
\end{tabular}

Table 2c. Example of change in evenness with size growing under way 3

\begin{tabular}{lcccccc}
\hline \hline & $\begin{array}{c}\text { The number of } \\
\text { contacts in Cohort 1 }\end{array}$ & $\begin{array}{c}\text { The number of } \\
\text { contacts in Cohort 2 }\end{array}$ & $\begin{array}{c}\text { The number of } \\
\text { contacts in Cohort 3 }\end{array}$ & $\begin{array}{c}\text { Network } \\
\text { evenness }\end{array}$ & $\begin{array}{c}\text { Network } \\
\text { size }\end{array}$ & Diversity \\
\hline Step 1 & 5 & 5 & 5 & 1 & 15 & 0.67 \\
Step 2 & 6 & 5 & 5 & 0.99 & 16 & 0.66 \\
Step 3 & 7 & 5 & 5 & 0.97 & 17 & 0.66 \\
Step 4 & 7 & 6 & 5 & 0.98 & 18 & 0.66 \\
\hline \hline
\end{tabular}

Table 2d. Example of change in evenness with size growing under way 4

\begin{tabular}{lcccccc}
\hline \hline & $\begin{array}{c}\text { The number of } \\
\text { contacts in Cohort 1 }\end{array}$ & $\begin{array}{c}\text { The number of } \\
\text { contacts in Cohort 2 }\end{array}$ & $\begin{array}{c}\text { The number of } \\
\text { contacts in Cohort 3 }\end{array}$ & $\begin{array}{c}\text { Network } \\
\text { evenness }\end{array}$ & $\begin{array}{c}\text { Network } \\
\text { size }\end{array}$ & Diversity \\
\hline Step 1 & 5 & 5 & 5 & 1 & 15 & 0.67 \\
Step 2 & 6 & 5 & 5 & 0.99 & 16 & 0.66 \\
Step 3 & 7 & 5 & 5 & 0.97 & 17 & 0.66 \\
Step 4 & 8 & 5 & 5 & 0.95 & 18 & 0.65 \\
\hline \hline
\end{tabular}


Hypothesis 4: The relationship between the size of a knowledge worker's egocentric network and the knowledge worker's job performance will be mediated by the dispersion richness of the knowledge worker's egocentric network.

\section{METHOD}

\section{Sample}

We collected data for $93 \mathrm{R} \& \mathrm{D}$ engineers from the $\mathrm{R} \& \mathrm{D}$ department of a SinoGerman joint venture company operating in Shanghai, China that supplies carmakers with innovative automobile electronics. This company, founded in 1995, employs over 1,000 workers; its revenue in 2007 was USD 187 million. Data was gathered from two main sources: a) a survey of the 93 engineers in the R\&D department; and b) matched data supplied by the Human Resource (HR) department. Data on ties, gender, age, and level of education was gathered using the survey, while data on job performance and other demographic data were supplied by HR.

\section{Questionnaire Design}

As prior studies on correlations between individual connections and performance focus on knowledge exchange relationships (e.g., Cross \& Cummings, 2004; McFadyen \& Cannella, 2004), we also collected the relationship data on knowledge transfer between individuals.

In gathering data we were careful to distinguish between knowledge exchange and information exchange. Huber (1991: 89) differentiates information as 'data that give meaning by reducing ambiguity, equivocality or uncertainty', whereas knowledge involves 'more complex products of learning, such as interpretations of information, beliefs about cause-and-effect relationships or more generally knowhow'. A preliminary investigation found that respondents were apt to confound notions of information with knowledge. With the aim of helping respondents differentiate between information sharing connections and knowledge transfer relationships, we designed an instrument asking about both, including previously validated questions adopted and adapted from Kaše, Paauwe, and Zupan (2009) on information exchange, and from Borgatti and Cross (2003) on knowledge exchange. We are only concerned with the knowledge transfer relationships among employees, thus the purpose of the information sharing question, and words regarding 'means and value of knowledge transfer' in the knowledge transfer questions, is to help the respondents distinguish between the relationships of information sharing and knowledge transfer.

As is typical in social network research, the data on each type of relationship is obtained with name generators that ask respondents to enumerate those individuals with whom they have direct ties of a specified kind (Marsden, 1990). We first 
asked the information-sharing question: 'In the past three months, from whom did you often seek information (e.g., information about processes, technology and customers)?' We then asked three knowledge transfer questions: (i) 'In the past three months, to whom did you often turn for knowledge on work-related topics?'; (ii) 'Through which means did he/she transfer the knowledge to you (e.g., electronic documents, print documents or face-to-face communication)?'; and (iii) 'How valuable was his/her help?'

The answers to the knowledge transfer questions rather than the informationsharing question were used to form the egocentric network data for analysis in this study. Marsden (1990: 456) suggests that such data is largely reliable when appropriate procedures are followed; these include ensuring that meaning is shared between respondents and investigators, and avoiding 'excessively diffuse and excessively minute items'. In this study, the questions are specific in order to elicit frequent interactions rather than one-time events, and the exact meaning of measures was conveyed to respondents by distinguishing knowledge transfer relationships from information sharing connections.

\section{Procedure}

Seeking an especially high survey response rate, we conducted a pre-test, comparing two methods of data collection. Pre-test respondents came from the sales department. Under Method A, the HR managers sent an email to the respondents with the confidentiality statement and questionnaire attached, and the respondents forwarded the completed questionnaires to the research team. Under Method B, respondents individually met with a member of our research team who introduced the study and confidentiality statement and then asked whether they would be willing to complete a computer-administered questionnaire. In both methods, the confidentiality statement promised that all the personal information and answers would remain strictly confidential to the research team; the survey was solely for the purpose of academic research; only aggregate level data would be reported to the senior executives; and no judgment or evaluation of individuals would be made. We found that with Method A, only 30 percent of respondents sent back the questionnaires, while with Method B all respondents agreed to complete the questionnaire, and there were no invalid questionnaires. We therefore adopted Method B, and with strong support from the sponsor firm, all $93 \mathrm{R} \& \mathrm{D}$ employees (100 percent response rate) completed the questionnaire.

\section{Measures}

The dependent variable in this study is the knowledge worker's job performance which focuses on innovativeness. The study firm bases its semi-annual employee 
evaluation on several key measures. First, at the end of every quarter, the supervisor interviews and evaluates each employee's performance on innovation. Second, to obtain different perspectives on the employee's performance, the firm's human resource function gathers feedback from co-workers who work closely with the employee. Additionally, semi-yearly, an executive evaluates these results, and makes a final decision mainly based on their performance on innovation, arriving at an overall rating on a ten-point scale. It was this overall rating that was used as the measure of job performance in the study. While this rating may be seen as somewhat subjective, it is based on data from multiple sources and is regarded within the organization as reliably reflecting job performance. The collection of social network data occurred eight weeks before the performance evaluation was conducted and asked about knowledge-exchange activities that happened 'in the past three months', ensuring that the data reflected the networks in existence during the period covered by the semi-yearly performance evaluation; thus the possibility of reverse causality that job performance impacts the network data can be excluded according to Xiao and Tsui (2007).

There are three independent variables: network size; dispersion richness; and dispersion evenness.

Egocentric network size is the total number of connections reported by the respondent in the three cohorts. We classified the ties by gathering information on the hierarchical position of employees and their departments from the company HR officers. We identified and assigned each relation between ego and alter to one of the three types of ties (those within the department, those outside the department and those higher in the hierarchy). For the contacts higher up in the hierarchy, whether they were within or outside the same department as the focal employee, we considered them as part of the third cohort rather than belonging to the first and second cohort. The size of the knowledge worker's egocentric network is simply their number of contacts.

Dispersion evenness and richness is derived from the network data provided by the respondent. As $E_{\frac{1}{D}}$ is suggested as one of the best evenness indices according to the requirement that the index should be independent of richness (Smith \& Wilson, 1996), we calculated dispersion evenness as Equation (1), where $S$ is the number of categories or cohorts.

$$
\begin{gathered}
E_{\frac{1}{D}}=\frac{1 / D}{S} \\
D=\sum_{i=1}^{S} p_{i}^{2}
\end{gathered}
$$


where

$$
p_{i}=\frac{n_{i}}{\mathcal{N}}
$$

and

$$
\mathcal{N}=\sum_{i=1}^{S} n_{i} .
$$

In Equations (3) and (4), $n_{i}$ is, respectively, the number of ties within the department, outside the department and higher up in the hierarchy.

Three richness configurations were also defined: (i) a network composed of one cohort (C1); (ii) a network composed of two cohorts (C2); and (iii) a network composed of three cohorts (C3). These dispersion richness categories are represented in the analysis by the numerals 1,2 and 3 , respectively.

\section{Control Variables}

We gathered information about each individual's age (in years), gender (dummy variable, 1 for male), education via the questionnaire, and collected data on tenure and hierarchical position from the HR department. Tenure was measured as length of time in fractional years. Education takes one of five values: $1=$ high school, $2=$ college, $3=$ bachelor's, $4=$ master's, $5=$ doctorate; the hierarchical position is assigned with one of the four values: $1=$ assistant, $2=$ associate engineer, $3=$ engineer, $4=$ manager .

\section{RESULTS}

Table 3 provides the means, standard deviations, and correlations for the variables used in the regression models. There are several observations to be made. Firstly, there are significant correlations between the dependent and independent variables, and the control variables, except education. Secondly, the correlation of tenure and hierarchical position with network size and its squared term (see Table 3) may suggest that the knowledge worker's social network grows over time and with seniority. Third, there are also significant correlations between egocentric network size and egocentric network size-squared. The correlation is more than 0.90 . Considering the high correlation between the egocentric network size and its squared term would introduce problems of multicollinearity, this study followed suggestions by Cronbach (1987) and the practices of Kratzer et al. (2008), McFadyen and Cannella (2004) and Wu and Shanley (2009), and centered the egocentric network size by subtracting from it the overall mean. The squared value incorporated into the regression analysis is the square of the centered variable. This helps to reduce correlation between the first power and second power terms, which becomes 0.728 . Lastly, dispersion evenness is highly correlated with dispersion richness. 
Size and Diversity of Social Network

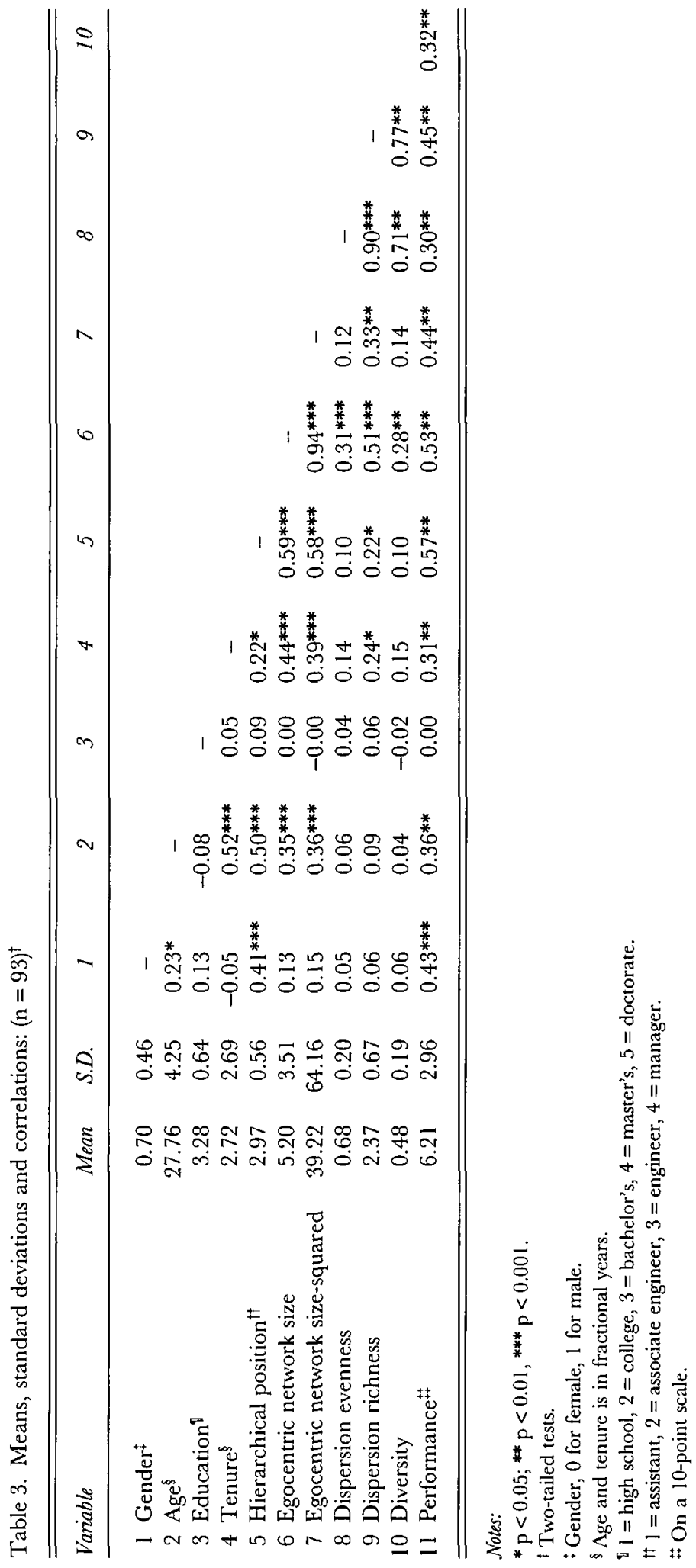

(C) 2012 The International Association for Chinese Management Research 


\section{Regression Analysis}

Ordinary least squares (OLS) regression results are reported in Tables 4 and 5 . In Table 4, the first model captures the control variables: gender, age, education, tenure and hierarchical position, where the coefficients of gender, tenure and hierarchical position are statistically significant. The relatively large amount of variance in the dependent variable explained by the control variables (39 percent) evidences, to some extent, the validity of the control variables. When the independent variables, egocentric network size and its squared term, are added to the second model there is a 7 percent improvement in the variance explained.

Hypothesis 1 predicted an inverted U-shaped relationship between the egocentric network size and job performance. For the data to support an inverted U-shaped relationship, the coefficient estimate for the egocentric network size should be significantly positive and the estimate for the corresponding squared term should be negative and significant, with a significant change in the model's explained variance. The results for Model 2 (Table 4) show that all of these conditions are met, thus the relationship between egocentric network size and job performance is statistically significant and inversely U-shaped. Hypothesis 1 is therefore supported.

Hypotheses 2 and 3 consider the effect of dispersion evenness and richness on job performance, respectively. In Model 3, both dispersion evenness and richness are

Table 4. Results of OLS regression analysis testing Hypotheses 1,2 , and $3(n=93)^{\dagger}$

\begin{tabular}{lcccc}
\hline \hline \multirow{2}{*}{ Variable } & \multicolumn{4}{c}{ Performance } \\
\cline { 2 - 5 } & Model 1 & Model 2 & Model 3 & Model 4 \\
\hline & 0.19 & 1.68 & -1.33 & -0.23 \\
Intercept & $1.90^{* *}$ & $2.02^{* *}$ & $1.94^{* *}$ & $1.93^{* *}$ \\
Gender & -0.05 & -0.01 & -0.02 & -0.00 \\
Age & -0.44 & 0.35 & -0.39 & -0.33 \\
Education & $0.30^{* *}$ & 0.16 & 0.14 & 0.15 \\
Tenure & $2.28^{* * *}$ & $1.48^{*}$ & $1.51^{*}$ & $1.54^{*}$ \\
Hierarchical position & & $0.40^{* *}$ & 0.18 & 0.32 \\
Egocentric network size & & $-0.03^{*}$ & -0.02 & -0.02 \\
Egocentric network size & & & -4.75 & \\
Dispersion Evenness & & & $2.32^{*}$ & \\
Dispersion Richness & & 0.46 & 0.49 & $2.20^{*}$ \\
Diversity & & 0.07 & 0.03 & -0.47 \\
Adjusted R-Squared & & 11.37 & 10.08 & 10.46 \\
Change in Adjusted R-Squared & 12.00 & 0.00 & 0.00 & 0.00 \\
F Statistics & 0.00 & & & \\
Sig. & & & & \\
\hline \hline
\end{tabular}

Notes:

${ }^{*} \mathrm{p}<0.05 ;{ }^{* *} \mathrm{p}<0.01,{ }^{* * *} \mathrm{p}<0.001$.

$\dagger$ Two-tailed tests. 
Table 5. Results of OLS regression analysis testing Hypothesis 4 $(\mathrm{n}=93)^{\dagger}$

\begin{tabular}{lcc}
\hline \hline \multirow{2}{*}{ Variable } & \multicolumn{2}{c}{ Dispersion richness } \\
\cline { 2 - 3 } & Model 5 & Model 6 \\
\hline Intercept & 2.10 & 2.82 \\
Gender & 0.03 & 0.08 \\
Age & -0.03 & -0.01 \\
Education & 0.00 & 0.05 \\
Tenure & $0.07 *$ & -0.00 \\
Hierarchical position & 0.29 & -0.09 \\
Egocentric network size & & $0.20^{* * *}$ \\
Egocentric network size ${ }^{2}$ & & $-0.01^{* * *}$ \\
Adjusted R-Squared & 0.05 & 0.43 \\
Change in Adjusted R-Squared & & 0.38 \\
F Statistics & 1.90 & 9.97 \\
Sig. & 0.10 & 0.00 \\
\hline \hline Notes: & & \\
${ }^{*}$ p<0.05;** $p<0.01, * * * p<0.001$. & & \\
${ }^{\dagger}$ Two-tailed tests. & &
\end{tabular}

included. The result shows that the coefficient estimate for dispersion evenness is negative and not significant, while the corresponding value for dispersion richness is significant and positive. Thus Hypothesis 3 is supported but Hypothesis 2 is not.

Hypothesis 4 proposes that the dispersion richness of a knowledge worker's egocentric network mediates the relationship between network size and job performance. Baron and Kenny (1986) describe a procedure for testing mediation which is widely accepted and has been used to examine the mediating effect on a U-shaped curvilinear relationship by Lado, Dant, and Tekleab (2008) and Li, Guo, Yi, and Liu (2010). Li et al. (2010:91) say that 'while most existing studies examine the mediating effect of linear relations... the mediation relation can also be non-linear and must be tested empirically by applying ordinary least squares regressions'. Using Baron and Kenny's (1986: 1176) procedure, network dispersion richness can be considered to function as a mediator when it meets the following three conditions. First, 'variations in levels of the independent variable significantly account for variations in the presumed mediator'; in fact, the egocentric network size and its squared term have a significant impact $(\mathrm{p}<0.001)$ on the mediator as shown in Model 6 (see Table 5). Second, 'variations in the mediator significantly account for variations in the dependent variable'; it is evident in Model 3 (see Table 4) that dispersion richness has a positive impact $(p=0.022)$ on the dependent variable. Third, when the effect of the presumed mediator is controlled, ' $a$ previously significant relation between the independent and dependent variables is no longer significant'; as shown in Model 3 (see Table 4) the significant effect of the 
egocentric network size and its squared term on the dependent variable disappears once we control for the effect of dispersion richness. Thus, as predicted by Hypothesis 4, taking the dispersion richness of the egocentric network into account removes any effect of the egocentric network size and its squared term.

We did a robustness check by adding the diversity index, namely Blau's index (for this measure refer to Harrison \& Klein, 2007), into Model 2 and derived Model 4. As this diversity index is decomposed into dispersion evenness and richness, the model with these two indices should account for more variance than that with only the diversity index. It is evident that the variance explained in Model 3 is greater than that in Model 4 by 0.02 .

All models were tested for violations of multicollinearity with no evidence found. The two highest VIF (variable inflation factor) values occurred in Model 3 where both results of dispersion evenness and richness are 6.6 and 8.3, respectively; the VIF value in other models are no greater than 5 . As all the VIF results are well below the standard cut-off of 10 , the possibility of multicollinearity can be excluded.

To show the inverted U-shape of the relationship between egocentric network size and performance and to facilitate its interpretation, we plotted this relationship. According to Model 2 in Table 4, performance $(P)$ is the function of egocentric network size (size), its squared term (size-squared) and five control variables (gender, age, education, tenure, and hierarchical position). For the convenience of plotting, we reduced these control variables to their mean values as suggested in other studies (e.g., Li et al., 2010). When substituting the five control variables with their mean values as shown in Table 3 , the constant term of the regression equation in Model 3 changes and the equation is derived as Equation 5:

$$
P=6.30+0.40 * \operatorname{siz}^{\prime}-0.03 * \operatorname{siz}^{\prime 2}
$$

Then, we transformed the centered egocentric network size to its initial value as shown in Formula 1. This replacement leads to the changes in coefficients of the constant term, and egocentric network size. As a result, we derived Equation 6 by putting Formula 1 into Equation 5.

$$
\begin{gathered}
\text { size } e^{\prime}=\text { size }- \text { mean of size } \\
P=3.41+0.52 * \text { size }-0.03 * \text { size }{ }^{2} .
\end{gathered}
$$

According to Equation 6, we plotted the curvilinear relationship between egocentric network size and performance, namely size takes the number incrementally from 1 till the numeral (but this numeral is not included) where the result of $P$ turns 
Figure 2. Inverted $\mathrm{U}$-shaped relationship between egocentric network size and performance

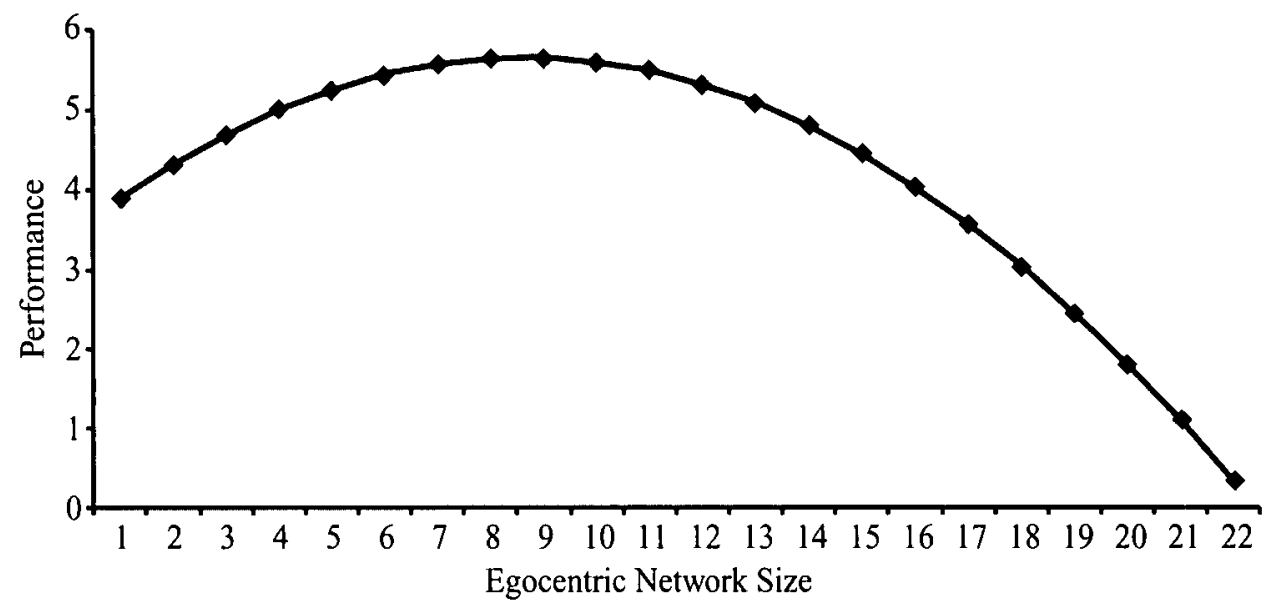

from a positive to a negative value for the first time. As shown in Figure 2, the initial increase in egocentric network size improves performance. The highest level of performance occurs when

$$
\frac{\partial P}{\partial \operatorname{size}}=\frac{\partial}{\partial \operatorname{size}}\left(3.41+0.52 * \text { size }-0.03 * \text { size } e^{2}\right)=0 .
$$

The solution for Equation 7 indicates that performance reaches its highest value when egocentric network size is 9 . However, when egocentric network size increases beyond this point there is an increasingly negative impact on performance.

\section{DISCUSSION}

Empirical results reported herein have shed light on the effects of the size and diversity of the knowledge worker's egocentric network and their relative importance, and yielded several contributions.

First, we contribute to the literature on network theory with our dissection of the operational measurement of diversity. Previous literature using entropy or Blau's index to characterize diversity seldom differentiates the two components of diversity: dispersion richness and evenness (e.g., Ancona \& Caldwell, 1992; Cummings, 2004; Harrison \& Klein, 2007; Oh et al., 2004; Reagans \& McEvily, 2003; Reagans \& Zuckerman, 2001; Teachman, 1980). We made such a differentiation and derived a deeper insight into the operational measurement of diversity by demonstrating the significant effect of network dispersion richness on the knowledge worker's job performance. Additionally, research addressing diversity as evenness in organizations is rare (Harrison \& Klein, 2007); we examined the effect 
of network dispersion evenness on performance and found such effect is insignificant. Furthermore, the correlation of diversity (Blau's index) with dispersion richness is larger than that with dispersion evenness (see Table 3). Hence, it is evident that dispersion richness of contacts is more important than dispersion evenness of contacts in the knowledge intensive industry.

A second contribution to the literature on individual social capital is both the demonstration of how individual network size produces network diversity, and the finding that network dispersion richness mediates the relationship between network size and job performance. We argue that network size is a necessary condition for network dispersion richness, but is uncorrelated with network dispersion evenness, and found that the dispersion richness of employee ties to disparate knowledge bases mediates the effect of network size on performance. This is consistent with the case study findings of Cross and Thomas (2008). They identified a director, who attributed his successful promotion to the senior executive ranks to his network; and though network analysis revealed his network was not the largest, he had the broadest reach across different functions and hierarchical levels.

The third contribution is testing the notion of diminishing benefits from growing the number of employees' contacts, demonstrating in the study context that the size of a knowledge worker's egocentric network has first a positive, and then as growth exceeds a moderate level, a negative effect on job performance. Although McFadyen and Cannella (2004) derived similar findings, their study was conducted in the context of academic communities, i.e., the biomedical departments in two US universities, which is different from this study context. Scientists in the universities and R\&D engineers in firms partially share the same purpose, which is to create knowledge, but they differ in several ways. First, how they are organized differs. Scientists cooperate with each other mostly based on their personal research interests; however, $R \& D$ engineers are grouped together according to organizational needs and dictates. Second, scientists have research plans, but are not subjected to rigid timelines, while R\&D engineers are under pressure to meet deadlines, as they must develop new technology and products on time or their organization will not be competitive. Third, scientists are relatively equal, while there are clear superior-subordinate relationships in the R\&D department, where subordinates receive direct orders from, and report directly to, their superiors. Finally, scientists mostly seek support from those colleagues who are in the same research area, while $R \& D$ engineers turn to persons not only within their department who have the same knowledge base, but those outside their department, higher in hierarchy, even customers who have disparate expertise and talent. Thus this study finding is also a contribution to the literature on individual social capital.

Additionally, the dependent variable is significantly correlated with the control variables, except education (as shown in Table 3). According to Becker (1964), 
enterprise knowledge can be classified into general knowledge and firm-specific knowledge. School-based education provides individuals with general knowledge. Firm-specific knowledge is embedded in the organization and is hard to imitate and trade and hence builds up the firm's competitive advantage (Wernerfelt, 1984). Preliminary interviews with executives and a review of existing documents on the number of patents applied for each year and market-share indicated that this company had grown their competitive capability by creating and accumulating firm-specific knowledge. The knowledge that the R\&D engineers in this study use to accomplish tasks is largely firm-specific. When the $R \& D$ engineers initially join the department, the level of education they possess is merely the foundation for learning and absorbing the firm-specific knowledge, which takes time and effort. Thus, we see a significant correlation between tenure and performance, rather than between education and performance.

Finally, dispersion evenness is highly correlated with dispersion richness (as shown in Table 3). This result is consistent with the argument that richness significantly correlates with evenness (Smith \& Wilson, 1996) and the indications of mathematical models and simulations that demonstrate the relationships between evenness and richness are strongly positive (Stirling \& Wilsey, 2001).

\section{Limitations}

The insights gained from our study are important, but the study has several limitations. First, a larger sample from more than one organization would increase confidence in the findings. Second, replication of this work across other kinds of organizations and populations will further allow generalisability. Though most bounded social network studies have drawn generalizations from a single organization (e.g., Cummings \& Cross, 2003) in order to achieve a valid and reliable performance metric (dependent variable), we encourage further research aimed at broadening the sample of organizational settings.

A further limitation of the study is the single, overall measure of each employee's job performance. Although the evaluation of job performance in this study is mainly based on innovation, other factors are also included, e.g., the perception of the focal employee from his or her colleagues and supervisors. Thus, in the future, a 'pure' measure of innovation may yield further insights into the relationship between the individual's egocentric network and innovation. Additionally, employing a subjective performance measure is not ideal. The organizational status of the focal employee and his or her relationship with executives could to some extent influence the result of evaluation; indeed, this may have influenced the significant correlation between performance and hierarchical position observed in Table 3. However, it is also possible that beyond friendship with higher-ups, it is the higher performers that advance to higher levels in the 
hierarchy. Moreover, we did not collect data on extra-organizational relationships owing to the difficulty in obtaining such data; this is another valuable possible extension in future research.

\section{Directions for Future Research}

The study findings and above limitations suggest possible fruitful future research directions. It would be interesting to adopt a more sophisticated model of performance in anticipation of different configurations of the egocentric network being associated with different dimensions of performance (e.g., efficiency, effectiveness, and innovation). It might be anticipated, where team cooperation is critical, networks dominated by contacts within the department result in higher efficiency and effectiveness, whereas networks with more ties across departments might lead to greater innovation. Further, most of the research on individual egocentric networks has studied R\&D engineers; yet the knowledge exchange networks of employees in other functions, such as sales engineers, mid-level managers and top management, also warrant investigation. Other employees have quite different roles to $\mathrm{R} \& \mathrm{D}$ engineers and the optimal configuration of their egocentric networks may be quite different. Additionally, most scholars studying ties to those higher in the hierarchy simply focus on the number of such ties, e.g., Seibert et al. (2001) and few have considered the distance (e.g., number of levels) between the subordinate and superior. Superiors in disparate hierarchical levels can provide differing information and support, thus the influence of contacts in different hierarchical positions may also vary. Moreover, this study demonstrates the curvilinear effect of network size on job performance is mediated by network dispersion richness, but does not provide an explanation of the dynamics of such an effect. Future research may examine how network size affects network dispersion richness and derive corresponding theoretical insights. Furthermore, we found that the number of contacts within and outside the department is significantly correlated (not shown in this study), namely, the knowledge worker who has more contacts within the department is more likely to have a greater number of contacts outside the department. This could be the result of both individual personality and organizational policy. When the individual is energetic and sociable, he or she is more likely to make friends within the department. In addition, organizations in China encourage employees to develop relationships across departments that go beyond the workplace, to social and leisure activities (Chai \& Rhee, 2010), and to develop stronger guanxi ties to facilitate knowledge sharing (Walsh, Bhatt, \& Bartunek, 2009). Consequently, the employee who has more contacts within the department will have a larger number of contacts outside the department. Hence, it is worth examining the impact of individual personality and organizational efforts on the development of personal social network. As Walsh et al. (2009) suggest different organizational forms, e.g., state-owned enterprises (SOEs), township and village 
enterprises, domestic private firms, and equity-based joint ventures, emphasize disparate knowledge creation patterns, such as internalization, externalization, socialization and combination; it is therefore reasonable that organizations of different forms would exert disparate efforts to encourage or discourage employees to develop personal social networks within organizations. Thus, to explore the relations between organizational forms and a knowledge worker's egocentric network structure and its influence on individual knowledge, creation patterns also deserve attention. Lastly, Li, Yao, Sue-Chan, and Xi (2011) argue that managers of SOEs have more governmental ties than their counterparts in non-state-owned enterprises (NSOEs). Studies to examine whether the different social network structure of managers in SOEs and NSOEs will contribute differently to their job performance and the organization's performance can further our understanding of the importance of governmental ties in China and how managers' social networks contribute to job performance.

\section{Managerial Implications}

Our results provide important insights into the management of egocentric networks, relevant to both knowledge workers and their managers. The importance of social capital has been widely recognized; however, the optimal configuration of an individual egocentric network has rarely been empirically examined. Many corporate executives have jumped to the conclusion that it is always better for an employee to have more contacts (Cross, Nohria, \& Parker, 2002), and books have proliferated that assume the secret to becoming a 'power' networker is a large network (Cross \& Thomas, 2008). This article highlights the opportunity cost of identifying, developing, and maintaining relationships, and argues that the size of the knowledge worker's egocentric network has an inverted U-shaped effect on job performance. Thus, practically, managers can take measures to encourage individuals to construct diverse egocentric networks, and monitor developments (rather than leave this entirely to individuals unchecked). Knowledge workers should understand that their performance can be enhanced by configuring their egocentric networks. Both managers and knowledge workers should be aware that a minimum of contacts is necessary and important, but that constantly increasing the number of relationships eventually results in diminishing returns. In addition to managing the size of one's egocentric network, more attention should be paid to managing the diversity of a knowledge worker's ties to different cohorts of colleagues. Knowledge workers require a broad range of knowledge and diverse perspectives to deal with novel problems; thus, diverse connections across individuals within their own department, outside their department, and higher in the organizational hierarchy can facilitate the combination of disparate and valuable knowledge, information and perspectives, and thus facilitate knowledge creation. 


\section{CONCLUSION}

Our empirical findings suggest that knowledge worker's egocentric network size has an inverted U-shaped effect on job performance. Furthermore, networks that span multiple cohorts or groups (dispersion richness) rather than having equal proportion of ties within the multiple cohorts (dispersion evenness) positively contribute to the knowledge worker's job performance. We further show that the effect of network size on job performance is due to dispersion richness in the networks. We hope this study will encourage more research exploring the optimal configuration of an individual's egocentric network in both Chinese and Western contexts.

\section{NOTES}

We are grateful to Anne Tsui (Editor-in-chief) and the two anonymous reviewcrs for their insightful and inspiring comments on earlier versions of this paper. We also thank the National Natural Science Foundation of China (project no. 71001040 and no. 71102167 ) for their financial grants. We acknowledge the highly professional assistance and intellectual input of research assistant Karen Stark. An earlier version of this work was presented at the 2010 IACMR Conference in Shanghai, China.

\section{REFERENGES}

Alatalo, R. V. 1981. Problems in the measurement of evenness in ecology. Oikos, 37(2): 199-204. Allen, T. 1970. Communication networks in R\&D laboratories. R\&D Management, 1(1): 14-21.

Allen, T. 1977. Managing the flow of technology: Technology transfer and the dissemination of technological information zeithin the R\&D organization. Cambridge, MA: MIT Press.

Ancona, D., \& Caldwell, D. 1992. Demography and design: Predictors of new product team performance. Organization Science, 3(3): 321-341.

Anderson, M. H. 2008. Social networks and the cognitive motivation to realize network opportunities: A study of managers' information gathering behaviors. Journal of Organizational Behavior, 29(1): 51-78.

Baron, R. M., \& Kenny, D. A. 1986. The moderator-mediator variable distinction in social psychological rescarch: Conceptual, strategic, and statistical considerations. Joumal of Personality and Social Psychology, 51(6): $1173-1182$.

Becker, G. S. 1964. Human capital: A theoretical and empirical analysis, zeith special reference to education. New York: National Bureau of Economic Research.

Borgatti, S. P., \& Cross, R. 2003. A relational view of information seeking and learning in social networks. Management Science, 49(4): 432-445.

Brass, D. J. 1984. Being in the right place: A structural analysis of individual influence in an organization. Administrative Science Quarterly, 29(4): 518-539.

Brass, D. J. 1992. Power in organizations: A social network perspective. In G. Moore \& J. A. White (Eds.), Research in politics and society, 4: 295-323. Greenwich, CT: JAI Press.

Burt, R. S. 1992. Structural holes: The social structure of competition. Cambridge, MA: Harvard University Press.

Campbell, K. E., Marsden, P. V., \& Hurlbert, J. S. 1986. Social resources and sociocconomic status. Social Networks, 8(1): 97-117.

Carroll, G., \& Teo, A. 1996. On the social networks of managers. Academy of Management Joumal, 39(2): $42 \mathrm{l}-440$.

Chai, S.-K., \& Rhee, M. 2010. Confucian capitalism and the paradox of closure and structural holes in East Asian firms. Management and Organization Revieze, 6(1): 5-29. 
Clark, K., \& Fujimoto, T. 1991. Product development performance. Boston, MA: Harvard Business School Press.

Coleman, J. S. 1988. Social capital in the creation of human capital. American Journal of Sociology, 94: S95-S120.

Criscuolo, P., Dahlander, L., \& Salter, A. 2009. Outside in, inside out: The impact of knowledge heterogeneity, intra- and extra-organizational tics on innovative status. The Academy of Management Proceedings, 1-6.

Cronbach, L. J. 1987. Statistical tests for moderator variables: Flaws in analyses recently proposed. Psychological Bulletin, 102(3): 414-417.

Cross, R., \& Cummings, J. N. 2004. Tie and network correlates of individual performance in knowledge-intensive work. Academy of Management Joumal, 47(6): 928-937.

Cross, R., Parker, A., Prusak, L., \& Borgatti, S. P. 2001. Knowing what we know: Supporting knowledge creation and sharing in social networks. Organizational Dynamics, 30(2): 100120.

Cross, R., Nohria, N., \& Parker, A. 2002. Six myths about informal networks and how to overcome them. MIT Sloan Management Revieze, 43(3): 67-75.

Cross, R., \& Sproull, L. 2004. More than an answer: Information relationships for actionable knowledge. Organization Science, 15(4): 446-462.

Cross, R., \& Thomas, R. J. 2008. How top talent uses networks and where rising stars get trapped. Organizational Dynamics, 37(2): 165-180.

Cummings, J. N. 2004. Work groups, structural diversity and knowledge sharing in a global organization. Management Science, 50(3): 352-364.

Cummings, J. N., \& Cross, R. 2003. Structural properties of work groups and their consequences for performance. Social Networks, 25(3): 197-210.

Davis, S. M., \& Lawrence, P. R. 1977. Matrix. Reading, MA: Addison-Wesley.

De Graal, N., \& Flap, H. 1988. With a little help from my friends: Social resources as an explanation of occupational status and income in West Germany, the Netherlands and the United States. Social Forces, 67(2): 452-472.

Eisenhardt, K. M., \& Bourgeois, L. J. 1988. Politics of strategic decision making in high-velocity cnvironments: Toward a midrange theory. Academy of Management Joumal, 31(4): 737-770.

Gabbay, S. M., \& Leenders, R. T. A. J. 2001. Social capital in organizations: From social structure to the management of corporate social capital. In S. M. Gabbay \& R. T. A. J. Leenders (Eds.), Research in the sociology of organizations: 1-20. Oxford: JAI Press.

Galbraith, J. R. 1977. Organization design. Reading, MA: Addison-Wesley.

Gargiulo, M., \& Benassi, M. 2000. Trapped in your own net? Network cohesion, structural holes, and the adaptation of social capital. Organization Science, 11(2): 183-196.

Granovetter, M. 1973. The strength of weak ties. American Joumal of Sociology, 78: 13601380.

Hansen, M. T. 2000. Knowledge networks: Explaining effective knowledge sharing in multiunit companies. Organization Science, 13(3): 232-248.

Hargadon, A., \& Sutton, R. I. 1997. Technology brokering and innovation in a product development firm. Administrative Science Quarterly, 42(4): 716-749.

Harrison, D. A., \& Klein, K. J. 2007. What's the difference? Diversity constructs as separation, variety, or disparity in organizations. Academy of Management Revieze, 32(4): 1199-1228.

Hill, M. O. 1973. Diversity and evenness: A unifying notation and its consequences. Ecology, 54(2): $427-432$.

Huber, G. P. 1991. Organizational learning: The contributing processes and the literatures. Organization Science, 2(1): 88-115.

Kaše, R., Paauwe, J., \& Zupan, N. 2009. HR practice, interpersonal relations, and intrafirm knowledge transfer in knowledge-intensive firms: A social network perspective. Human Resource Management, 48(4): 615-639.

Kratzer, J., Leenders, R. T. A. J., \& Van Engelen, J. M. L. 2008. The social structure of leadership and creativity in engineering design teams: An empirical analysis. Joumal of Engineering and Technology Management, 25(4): 269-286.

Lado, A. A., Dant, R. R., \& Tekleab, A. G. 2008. Trust-opportunism paradox, relationalism, and performance in interfirm relationships: Evidence from the retail industry. Strategic Management Journal, 29(4): 401-423. 
Latour, B., \& Woolgar, S. 1979. Laboratory life: The construction of scientific facts. Beverly Hills, CA: Sage.

Li, S. X., Yao, X., Sue-Chan, C., \& Xi, Y. 2011. Where do social ties come from: Institutional framework and governmental ties distribution among Chinese managers. Management and Organization Review, 7(1): 97-124.

Li, Y., Guo, H., Yi, Y., \& Liu, Y. 2010. Ownership concentration and product innovation in Chinese firms: The mediating role of learning orientation. Management and Organization Review, $6(1): 77-100$.

Lin, N. 1999. Social networks and status attainment. In J. Hagan \& K. S. Cook (Eds.), Annual revieze of sociology, Vol. 25: 467-487. Palo Alto, CA: Annual Reviews.

Lin, N., Ensel, W. M., \& Vaughn, J. C. 1981. Social resources and strength of ties: Structural factors in occupational status attainment. American Sociological Revieze, 46(4): 393-405.

Lloyd, M., \& Ghelardi, R. J. 1964. A table for calculating the 'equitability' component of species diversity. The Joumal of Animal Ecology, 33(2): 217-225.

Luo, J.-D. 2011. Guanxi revisited: An exploratory study of familiar ties in a Chinese workplace. Management and Organization Revieze, 7(2): 329-351.

Marsden, P. 1990. Network data and measurement. Annual Revieze of Sociology, 16(1): 435463.

Marsden, P., \& Hurlbert, J. 1988. Social resources and mobility outcomes: A replication and extension. Social Forces, 66(4): 1038-1059.

McFadyen, M. A., \& Cannella, A. A. 2004. Social capital and knowledge creation: Diminishing returns of the number and strength of exchange relationships. Academy of Management Journal, 47(5): 735-745.

Mehra, A., Kilduff, M., \& Brass, D. J. 2001. The social networks of high and low self-monitors: Implications for workplace performance. Administrative Science Quarterly, 46(1): 121 146.

Mehra, A., Dixon, A. L., Brass, D. J., \& Robertson, B. 2006. The social network ties of group leaders: Implications for group performance and leader reputation. Organization Science, 17(1): $64-79$

Nahapiet, J., \& Ghoshal, S. 1998. Social capital, intellectual capital and the organizational advantage. Academy of Management Revieze, 23(2): 242-266.

Oh, H., Chung, M. H., \& Labianca, G. 2004. Group social capital and group effectiveness: The role of informal socializing ties. Academy of Management Journal, 47(6): 860-875.

Peet, R. K. 1974. The measurement of species diversity. Annual Review of Ecology and Systematics, 5: 285-307.

Perry-Smith, J. E., \& Shalley, C. E. 2003. The social side of creativity: A static and dynamic social network perspective. Academy of Management Revieze, 28(1): 89-106.

Pfeffer, J. 2010. Power. Why some people have it - and others don't. Harper Collins Publishers.

Reagans, R., \& McEvily, B. 2003. Network structure and knowledge transfer: The effects of cohesion and range. Administrative Science Quarterly, 48(2): 240-267.

Reagans, R., \& Zuckerman, E. W. 2001. Networks, diversity, and productivity: The social capital of corporate R\&D teams. Orgaization Science, 12(4): 502-517.

Seibert, S. E., Kraimer, M. L., \& Liden, R. C. 2001. A social capital theory of career success. Academy of Management Journal, 44(2): 219-237.

Simon, L., \& Davies, G. 1996. A contextual approach to management learning: The Hungarian case. Organization Studies, 17(2): 269-289.

Smith, B., \& Wilson, J. B. 1996. A consumer's guide to evenness indiccs. Oikos, 76(1): 70-82.

Smith, K. G., Collins, C., \& Clark, K. D. 2005. Existing knowledge, knowledge creation capability, and the rate of new product introduction in high-technology firms. Academy of Management Journal, 48(2): 346-357.

Stevenson, W., \& Gilly, M. 1991. Information processing and problem solving: The migration of problems through formal positions and network ties. Academy of Management Joumal, 34(4): 918-928.

Stirling, G., \& Wilscy, B. 2001. Empirical relationships between species richness, evenness, and proportional diversity. The American Naturalist, 158(3): 286-299.

Szulanski, G. 1996. Exploring internal stickiness: Impediments to the transfer of best practice within the firm. Strategic Management Journal, 17(Winter special issue): 27-43. 
Teachman, J. D. 1980. Analysis of population diversity. Sociology Methods \& Research, 8(3): $341-362$.

Tsai, W. 200l. Knowledge transfer in intraorganizational networks: Effects of network position and absorptive capacity on business-unit innovation and performance. Academy of Management Journal, 44(5): 996-1004.

Walsh, I. J., Bhatt, M., \& Bartunek, J. M. 2009. Organizational knowledge creation in the Chinese context. Management and Organization Review, 5(2): 261-278.

Wernerfelt, B. 1984. A resource-based view of the firm. Strategic Management Journal, 5(2): $171-180$.

Wong, S. 2008. Judgements about knowledge importance: The roles of social referents and network structure. Human Relations, 61(1 1): 1565-1591.

Wu, J., \& Shanley, M. T. 2009. Knowledge stock, exploration, and innovation: Research on the United States electromedical device industry. Journal of Business Research, 62(4): 474483.

Xiao, Z., \& Tsui, A. S. 2007. When brokers may not work: The cultural contingency of social capital in Chinese high-tech firms. Administrative Science Quarterly, 52(1): 1-31.

Liang Chen (sanlychen@126.com) is a lecturer at the School of Business, East China University of Science and Technology. He earned his Ph.D. from Antai College of Economics and Management, Shanghai Jiaotong University. His research interests include social networks, social capital, knowledge management, and complex networks.

Guy G. Gable (g.gable@qut.edu.au) is professor in the Information Systems School at Queensland University of Technology, Brisbane, Australia. His $\mathrm{Ph} . \mathrm{D}$. is from University of Bradford, England. He has over 100 refereed publications (e.g., Management Science, Joumal of the AIS, Joumal of Strategic Information Systems). He is broadly interested in measuring success, enterprise system, organizational social networks, and social capital.

Manuscript received: February 7, 2010

Final version accepted: April 16, 2012

Accepted by: Anne S. Tsui 